\title{
Complications of Endovascular Treatments for Brain Arteriovenous Malformations: A Nationwide Surveillance
}

\author{
(D) K. Sato, (D) Y. Matsumoto, (D). Tominaga, (D). Satow, (D). lihara, and DN. Sakai,
} for the Japanese Registry of Neuroendovascular Therapy Investigators

\begin{abstract}
BACKGROUND AND PURPOSE: Embolization is widely performed to treat brain arteriovenous malformations, but little has been reported on factors contributing to complications. We retrospectively reviewed a nationwide surveillance to identify risk factors contributing to complications and short-term clinical outcomes in the endovascular treatment of brain arteriovenous malformations.
\end{abstract}

MATERIALS AND METHODS: Data for endovascular treatment of brain arteriovenous malformations were extracted from the Japanese nationwide surveillance. Patient characteristics, brain arteriovenous malformation features, procedures, angiographic results, complications, and clinical outcomes at 30 days postprocedure were analyzed.

RESULTS: A total of 1042 endovascular procedures (788 patients; mean, $1.43 \pm 0.85$ procedures per patient) performed in 111 institutions from 2010 to 2014 were reviewed. Liquid materials were used in 976 procedures (93.7\%): to perform presurgical embolization in 638 procedures (61.2\%), preradiosurgical embolization in 160 (15.4\%), and as sole endovascular treatment in 231 (22.2\%). Complete or near-complete obliteration of brain arteriovenous malformations was obtained in 386 procedures (37.0\%). Procedure-related complications occurred in 136 procedures (13.1\%), including hemorrhagic complications in 59 (5.7\%) and ischemic complications in 57 (5.5\%). Univariate analysis identified deep venous drainage, associated aneurysms, infratentorial location, and preradiosurgical embolization as statistically significant risk factors for complications. Multivariate analysis showed that embolization of brain arteriovenous malformations in the infratentorial location was significantly associated with complications. Patients with complications due to endovascular procedures had worse clinical outcomes 30 days after the procedures than those without complications.

CONCLUSIONS: Complications arising after endovascular treatment of brain arteriovenous malformations are not negligible even though they may play a role in adjunctive therapy, especially in the management of infratentorial brain arteriovenous malformations.

ABBREVIATIONS: bAVM = brain arteriovenous malformation; JR-NET = Japanese Registry of Neuroendovascular Therapy

B rain arteriovenous malformations (bAVMs) are rare lesions characterized by the presence of a nidus containing abnormal tortuous vascular channels between feeding arteries and draining veins without an intervening capillary network. ${ }^{1}$ AVMs most commonly result in hemorrhage, which carries a mortality rate of $10 \% \sim 15 \%$ and a morbidity rate up to $50 \%$. $^{2}$ The annual hemorrhage rate for AVMs is between $2 \%$ and $4 \%$ per year. ${ }^{3-6}$ The main

Received October 14, 2019; accepted after revision January 10, 2020

From the Department of Neuroendovascular Therapy (K.S., Y.M.), Kohnan Hospital, Sendai, Japan; Department of Neurosurgery (T.T.), Tohoku Graduate School of Medicine, Sendai, Japan; Department of Neurosurgery (T.S.), National Cerebral and Cardiovascular Center, Suita, Japan; Department of Neurosurgery (K.I.), Graduate School of Medical Sciences, Kyushu University, Fukuoka, Japan; and Department of Neurosurgery (N.S.), Kobe City Medical Center General Hospital, Kobe, Japan.

This study was supported, in part, by a Grant-in-Aid (Junkanki-Kaihatsu H24-4-3) from the National Cerebral and Cardiovascular Center, Japan, and by Hatazaki Foundation, Kobe, Japan. goal of therapy is complete AVM obliteration, which prevents future hemorrhage. Current treatment options include microsurgery, radiosurgery, embolization, or a combination of therapies. ${ }^{7}$

Endovascular embolization has typically been reserved as an adjunctive therapy in the management of bAVMs, either for preoperative devascularization or preradiosurgical volume reduction. ${ }^{8}$ In addition, palliative or target embolization may be used in high-risk components of bAVMs to stabilize symptomatic lesions. ${ }^{9}$ Recent technical advances, including flow-

Please address correspondence to Kenichi Sato, MD, Department of Neuroendovascular Therapy, Kohnan Hospital, 4-20-1 Nagamachi-minami, Taihakuku, Sendai, Japan, 982-8523; e-mail: kenmina@nsg.med.tohoku.ac.jp

-- Indicates open access to non-subscribers at www.ajnr.org

$\equiv$ Indicates article with supplemental on-line tables.

http://dx.doi.org/10.3174/ajnr.A6470

AJNR Am J Neuroradiol 41:669-75 Apr 2020 www.ajnr.org 
directed microcatheters and liquid embolic materials such as n-BCA and ethylene-vinyl alcohol copolymer (Onyx; Medtronic, Irvine, California), make it possible to treat bAVMs with embolization alone in selected cases. ${ }^{10-12}$ With expanded capabilities, appropriate patient selection and risk estimation for the endovascular procedure for treatment of bAVMs becomes paramount. Nonetheless, studies of the complications of embolization using multicenter data collection have been scarce.

In this study, we retrospectively reviewed a nationwide surveillance to elucidate notable risk factors of procedure-related complications and short-term clinical outcomes after endovascular treatment of bAVMs.

\section{MATERIALS AND METHODS Data Extraction}

The Japanese Registry of Neuroendovascular Therapy (JR-NET) is a nationwide retrospective registration study. Clinical and procedural data were enrolled through a Web site constructed by the Translation Research Informatics Center (Kobe, Japan) and anonymously reviewed by the principal investigators. The institutional review board at Kobe City Medical Center General Hospital approved the study protocol of JR-NET. Because of the retrospective observational nature of the study, written informed consent was not obtained from patients. Previous studies have been reported on data from JR-NET1 and JR-NET2, which were conducted from 2005 to 2006 and 2007 to 2009 , respectively. ${ }^{13,14}$ A total of 40,169 endovascular procedures were reviewed in the JR-NET3 study from 2010 to 2014, including 1063 procedures (2.7\% of all procedures) for bAVMs treated by embolization. After excluding incomplete or duplicate data, we analyzed 1042 procedures performed for bAVMs for which detailed data were available.

JR-NET studies were performed according to the principles of the Declaration of Helsinki.

\section{Evaluation}

The dataset of patients with bAVMs obtained from JR-NET3 included the following: basic information (patient age, sex, symptoms, mRS score before the procedure, and mRS 30 days after the procedure) and detailed information about the lesions (nidus location, maximal diameter, involvement of the eloquent brain area, associated aneurysms, and the features of the draining vein, including deep venous drainage, occlusion, stenosis, and varix). AVMs were also classified according to the Spetzler-Martin grading system. ${ }^{15}$ Procedural data were documented, including the number of participating physicians, the number of procedures, scheduled or emergency procedures, embolization strategy, sensory-evoked potential and/or motor-evoked potential monitoring, provocation test, type of microcatheter and embolic material used, the number of feeding vessels cannulated, embolization results, and complications. The embolization strategy was defined as curative, target, presurgical, or preradiosurgical. Procedurerelated complications were classified as hemorrhagic (AVM rupture and vessel perforation), ischemic (vessel occlusion and distal embolism), or others. Clinical outcomes 30 days after endovascular procedures were dichotomized into favorable (mRS 0-2) or poor (mRS 3-6) for statistical analysis.

\section{Statistical Analysis}

Statistical analyses were performed using JMP software (Version 12; SAS Institute, Cary, North Carolina). Numeric data are expressed as mean \pm SD. Group comparisons of mean and categoric data were performed using the Student $t$ test and Pearson $\chi^{2}$ test as appropriate. $P$ values $<.05$ were considered statistically significant. A multivariate statistical analysis of factors related to the occurrence of complications was performed using a logistic regression model. Variables found to be significant in the univariate analysis were selected for testing in the final model.

\section{RESULTS}

\section{Patient Characteristics}

Table 1 summarizes the baseline characteristics of the study population. We reviewed 788 patients (471 males [59.8\%]; age range, 0-90 years; mean, 41.3 years of age) with bAVMs who underwent a total of 1042 embolization procedures $(1.43 \pm 0.85$ procedures per patient) in 111 institutions between January 2010 and December 2014. Clinical presentation was hemorrhage in 548 patients (69.5\%), while 110 patients were asymptomatic. A Spetzler-Martin grade was determined for 752 of the treated AVMs (95.4\%). There were 136 grade I (17.3\%), 273 grade II (34.6\%), 224 grade III (28.4\%), 98 grade IV (12.4\%), and 21 grade $\mathrm{V}(2.7 \%)$ lesions. AVMs were located in the cortical regions in 574 patients $(72.8 \%)$, were deep-seated in $35(4.4 \%)$, in the cerebellum in $126(16.0 \%)$, and in the brain stem in $17(2.2 \%)$. Associated aneurysms were found in 146 AVMs (18.5\%), including flow-related arterial aneurysms in 92 AVMs (11.7\%) and intranidal aneurysms in 45 (5.7\%). Abnormalities of the drainage route were detected in $290 \mathrm{AVMs}$ (36.4\%), including occlusion of the draining vein in $12(1.5 \%)$, stenosis in 92 (11.7\%), and venous varix in $186(23.6 \%)$.

\section{Modalities of Treatment}

Endovascular treatment for bAVMs included presurgical embolization in 638 procedures (61.2\%), preradiosurgical embolization in $160(15.4 \%)$, target embolization in $144(13.8 \%)$, and curative embolization in 87 (8.3\%). The purposes of the endovascular procedure were unknown in 13 (1.2\%). Presurgical embolization was performed in patients with AVMs of Spetzler-Martin grade I in $107(16.8 \%)$ procedures, grade II in 224 (35.1\%), grade III in 165 (25.9\%), grade IV in 91 (14.3\%), and grade V in 50 (7.8\%) (Online Table 1). Of all embolization procedures, 124 (11.9\%) were performed as an emergency procedure. Provocation and evokedpotentials were monitored in $117(11.2 \%)$ and 39 (3.7\%) procedures, respectively. Coils were used in 165 embolization procedures (15.8\%); $n$-BCA, in $627(60.2 \%)$; and Onyx, in 432 (41.5\%). An average of 3.3 embolization sessions per procedure was achieved. All procedures were performed via a transarterial approach.

\section{Treatment Results}

Technical success was achieved in 1023 procedures (98.2\%). Curative embolization achieved complete obliteration of the nidus in 55.2\% (48 procedures) and near-complete obliteration in $27.6 \%$ (24 procedures). Overall, endovascular procedures resulted in complete or near-complete obliteration of the AVM in $37.0 \%$ (386 procedures) and partial 


\begin{tabular}{|c|c|}
\hline Characteristics & \\
\hline No. of patients & 788 \\
\hline Age (mean) (yr) & $41.3 \pm 19.9$ \\
\hline Male (No.) (\%) & $471(59.8 \%)$ \\
\hline \multicolumn{2}{|l|}{ Clinical presentation (No.) (\%) } \\
\hline Hemorrhage & $548(69.5 \%)$ \\
\hline NHND & $130(16.5 \%)$ \\
\hline Asymptomatic & $110(14.0 \%)$ \\
\hline \multicolumn{2}{|l|}{ Preprocedural mRS (No.) (\%) } \\
\hline 0 & $562(71.3 \%)$ \\
\hline 1 & $84(10.7 \%)$ \\
\hline 2 & $44(5.6 \%)$ \\
\hline 3 & $34(4.3 \%)$ \\
\hline 4 & $27(3.4 \%)$ \\
\hline 5 & $15(1.9 \%)$ \\
\hline Unknown & 22 \\
\hline \multicolumn{2}{|l|}{ Spetzler-Martin grade (No.) (\%) } \\
\hline I & $136(17.3 \%)$ \\
\hline II & $273(34.6 \%)$ \\
\hline III & $224(28.4 \%)$ \\
\hline IV & 98 (12.4\%) \\
\hline V & $21(2.7 \%)$ \\
\hline Unknown & $36(4.6 \%)$ \\
\hline \multicolumn{2}{|l|}{ Size (No.) (\%) } \\
\hline$<3 \mathrm{~cm}$ & $443(56.2 \%)$ \\
\hline $3-6 \mathrm{~cm}$ & $278(35.3 \%)$ \\
\hline$>6 \mathrm{~cm}$ & $38(3.8 \%)$ \\
\hline Deep venous drainage (No.) (\%) & $438(55.6 \%)$ \\
\hline Eloquence (No.) (\%) & $318(40.4 \%)$ \\
\hline \multicolumn{2}{|l|}{ Location (No.) (\%) } \\
\hline Cortical & 574 (72.8\%) \\
\hline Deep & $35(4.4 \%)$ \\
\hline Cerebellum & $126(16.0 \%)$ \\
\hline Brain stem & $17(2.2 \%)$ \\
\hline Others & $36(4.6 \%)$ \\
\hline Associated aneurysm (No.) (\%) & $146(18.5 \%)$ \\
\hline Flow-related & $92(11.7 \%)$ \\
\hline Intranidal & $45(5.7 \%)$ \\
\hline Unrelated & $9(1.1 \%)$ \\
\hline \multicolumn{2}{|c|}{ Abnormality of drainage route (No.) (\%) } \\
\hline Occlusion & $12(1.5 \%)$ \\
\hline Stenosis & $92(11.7 \%)$ \\
\hline Varix & $186(23.6 \%)$ \\
\hline
\end{tabular}

Note:-NHND indicates nonhemorrhagic neurologic deficit.

obliteration in $60.3 \%$ (628 procedures). No morphologic changes were observed in the remaining 17 AVMs (1.6\%) based on postoperative radiologic examinations.

\section{Complications}

Complications occurred in 136 embolization procedures (13.1\%), with hemorrhage observed in 59 (5.7\%) and ischemia in 57 (5.5\%). Hemorrhagic complications included AVM rupture in 26 procedures $(2.4 \%)$ and vessel perforation or rupture due to catheterization in 33 (3.2\%). AVM rupture occurred intraoperatively in 8 procedures $(30.8 \%$ of patients with AVM rupture), within 24 hours after endovascular procedures in 9 $(34.6 \%)$, within 7 days in 5 (19.2\%), and within 30 days in 4 (15.4\%). Of the cases of AVM rupture, 12 patients $(46.2 \%$ of patients with AVM rupture) underwent emergency open surgery for removal of a hematoma as well as ruptured AVMs after embolization. Procedures with AVM rupture were associated with severe persistent disability in 8 patients $(30.8 \%$ of patients with AVM rupture), mild persistent disability in 2 (7.7\%), and transient neurologic deficits in 6 (23.1\%). Death occurred in 2 patients (7.7\%) with AVM rupture. There was no significant difference in patient characteristics, morphologic features of AVM, and the strategy, embolic materials, or results of the embolization between procedures with AVM rupture and those without.

Ischemic complications included normal artery occlusion in 34 procedures (59.6\% of patients with ischemic complications), distal thrombotic embolism in 20 (35.1\%), and arterial dissection due to catheterization in 3 (5.3\%). Procedures with ischemic complications were associated with severe persistent disability in 9 patients $(15.8 \%$ of patients with ischemic complications), mild persistent disability in 13 (22.8\%), and transient neurologic deficits in 12 (21.1\%).

Univariate analyses in regard to AVM features revealed that deep venous drainage $(P<.01)$, infratentorial location including the cerebellum $(P<.01)$ and/or brain stem $(P<.01)$, and the presence of flow-related aneurysms $(P=.01)$ were significantly correlated with procedure-related complications, while cortical location had a negative correlation with complications $(P<.01$, On-line Table 2). In relation to the type of endovascular procedure, preradiosurgical embolization was associated with procedure-related complications $(P<.05$, Table 2$)$. Infrantentorial location, including the cerebellum (OR, 2.38; 95\% CI, 1.25-3.16) and brain stem (OR, 2.14; 95\% CI, 1.48-10.13), remained significantly associated with procedure-related complications in a multivariate analysis $(P<.01)$. AVM rupture (7/147, 4.8\%) and ischemia (14/147, 9.5\%) occurred more frequently in cerebellar AVMs than AVMs in other regions $(16 / 895,1.8 \%, P<.05$, and $40 / 895,4.5 \%, P<.01$, respectively), while ischemic complications $(6 / 20,30 \%)$ occurred more frequently in brain stem AVMs than in other regions (48/1022, $4.7 \%, P<.01)$.

\section{Clinical Outcomes}

The 30-day morbidity and mortality rates were 291 (27.9\%) and $8(0.8 \%)$ of 1042 procedures, respectively. Two of the 8 deaths were accompanied by hemorrhagic complications (AVM rupture, $n=2$ ). Endovascular procedures with complications were significantly associated with worse outcome compared with procedures without complications $(P<.05$, Table 3$)$.

To determine the risk factors associated with the deterioration of mRS scores, we compared the procedures that led to worse mRS scores 30 days after the endovascular procedures and those in which mRS scores of patients improved or did not change (On-line Table $3)$. Univariate analyses revealed that older age $(P \leq .001)$, hemorrhagic presentation $(P \leq .001)$, nidus size $\leq 3 \mathrm{~cm}(P=.001)$, infratentorial nidus location $(P \leq .001)$, presurgical embolization $(P=$ $.021)$, complete obliteration $(P=.003)$, and procedure-related complications $(P \leq .001)$ were significantly correlated with the deterioration of $\mathrm{mRS}$ scores 30 days after endovascular treatment. Older age ( $P=.026$; OR, 0.99; 95\% CI, 0.99-1.0), hemorrhagic presentation $(P \leq .001$; OR, 4.05; 95\% CI, 2.91-5.73), presurgical embolization $(P=.002$; OR, 1.56 ; 95\% CI, 1.17-2.09), complete obliteration ( $P=$ .021 ; OR, 1.71; 95\% CI, 1.08-2.69), and procedure-related complications ( $P \leq .001$; OR, 2.02; 95\% CI, 1.36-3.02) remained significantly associated with the deterioration of $\mathrm{mRS}$ scores 30 days after endovascular treatment in a multivariate analysis. 


\begin{tabular}{|c|c|c|c|c|c|c|}
\hline & \multirow[b]{2}{*}{ Total } & \multicolumn{2}{|c|}{ Complication } & \multicolumn{2}{|c|}{$P$ Value } & \multirow[b]{2}{*}{ OR $(95 \% \mathrm{Cl})$} \\
\hline & & Yes & No & Uni- & Multi- & \\
\hline No. of procedures (\%) & 1042 & $136(13.1 \%)$ & $906(86.9 \%)$ & & & \\
\hline Emergency (No.) (\%) & 124 & $13(9.6 \%)$ & 111 (10.6\%) & .366 & & \\
\hline Provocation test (No.) (\%) & 117 (11.2\%) & $8(5.9 \%)$ & $109(12.0 \%)$ & .059 & & \\
\hline SEP and/or MEP monitoring (No.) (\%) & $39(3.7 \%)$ & $7(5.1 \%)$ & $32(3.5 \%)$ & .561 & & \\
\hline \multicolumn{7}{|l|}{ No. of treatments (No.) (\%) } \\
\hline Initial & $778(75.6 \%)$ & $104(76.5 \%)$ & $684(75.5 \%)$ & .48 & & \\
\hline Second and more & $254(24.4 \%)$ & $32(23.5 \%)$ & $222(24.5 \%)$ & .48 & & \\
\hline \multicolumn{7}{|l|}{ Strategy (No.) (\%) } \\
\hline Curative & $87(8.3 \%)$ & $17(12.5 \%)$ & $70(7.7 \%)$ & .061 & & \\
\hline Target & $144(13.8 \%)$ & 15 (11.0\%) & $129(14.2 \%)$ & .312 & & \\
\hline Presurgical & $638(61.2 \%)$ & $74(54.4 \%)$ & $564(62.3 \%)$ & .08 & & \\
\hline Preradiosurgical & $160(15.4 \%)$ & 29 (21.3\%) & 131 (14.5\%) & .038 & .074 & $1.13(0.96-2.44)$ \\
\hline No. of approaches (mean) & & $3.2 \pm 1.2$ & $3.3 \pm 1.5$ & .28 & & \\
\hline \multicolumn{7}{|l|}{ Embolic material (No.) (\%) } \\
\hline Coils & 165 (15.8\%) & $16(11.8 \%)$ & 149 (15.3\%) & .163 & & \\
\hline$n-B C A$ & $627(60.2 \%)$ & $83(61.0 \%)$ & $544(60.0 \%)$ & .827 & & \\
\hline Onyx & $432(41.5 \%)$ & $64(47.1 \%)$ & $368(40.6 \%)$ & .073 & & \\
\hline \multicolumn{7}{|l|}{ Results (No.) (\%) } \\
\hline Complete obliteration & $101(9.7 \%)$ & $18(13.2 \%)$ & $83(9.2 \%)$ & .134 & & \\
\hline Nearly complete & $285(27.3 \%)$ & $38(27.9 \%)$ & $247(27.3 \%)$ & .869 & & \\
\hline Partial & $628(60.3 \%)$ & $76(55.9 \%)$ & $552(60.9 \%)$ & .262 & & \\
\hline Unchanged & $17(1.6 \%)$ & $3(2.2 \%)$ & $14(1.5 \%)$ & .571 & & \\
\hline
\end{tabular}

Note:-SEP indicates sensory-evoked potential; MEP, motor-evoked potential.

Table 3: $\mathrm{mRS}$ at 30 days after endovascular procedure

\begin{tabular}{lcccc}
\hline & & \multicolumn{2}{c}{ Complications } & \\
\cline { 3 - 4 } & Total & Yes & No & Univariate (P Value) \\
\hline No. of Procedures (\%) & 1042 & $136(13.1 \%)$ & $906(86.9 \%)$ & \\
mRS score (No.) (\%) & & & & \\
$0-2$ & $743(71.3 \%)$ & $87(64.0 \%)$ & $656(72.4 \%)$ & .046 \\
$3-6$ & $299(28.7 \%)$ & $49(36.0 \%)$ & $250(27.6 \%)$ & .046 \\
\hline
\end{tabular}

neurologic deficits). ${ }^{26,27}$ After the introduction of Onyx for AVM embolizations, Bell et $\mathrm{al}^{25}$ reported their experience of transarterial embolization in 126 patients with bAVMs and concluded that procedure-related complications did not correlate with the Spetzler-Martin

\section{DISCUSSION}

We reviewed 1042 AVM embolization procedures using data extracted from a nationwide surveillance (JR-NET3). Of all the cases reviewed, $13.1 \%$ experienced complications, including hemorrhage in $5.7 \%$ and ischemia in $5.5 \%$, which are consistent with the reported rates of complications in $6.4 \%-21 \%$ of procedures. ${ }^{16-22}$ Multivariate analysis showed that embolization for infratentorial AVMs was significantly associated with complications. To our knowledge, this study includes the largest number of patients with bAVMs treated by endovascular procedures across multiple centers since the advent of current neuroendovascular techniques.

With the advances in neuroendovascular treatment throughout the past 2 decades, new techniques and devices have improved the possibility for successful embolization of bAVMs, alone or in combination with other therapeutic modalities. ${ }^{17,23,24}$ Despite the fairly large number of patients with bAVMs who are treated with embolization, published data on complications associated with embolization procedures are surprisingly scarce or only based on the experience of a single institution. Refinement of bAVM risk assessment for endovascular treatment is imperative in ensuring favorable outcome. $^{25}$

In the pre-Onyx era, endovascular treatment for bAVMs was deemed to carry a procedural risk related to the SpetzlerMartin grade, number of embolizations treated, and the patient characteristics (increased age and absence of pretreatment grade, but with a novel endovascular grading scale incorporating the number of feeding arteries, eloquence, and the presence of an arteriovenous fistula component. Pan et al ${ }^{19}$ categorized complications of AVM embolization using liquid materials into technique-related and non-technique-related. Techniquerelated complications, such as those induced by navigation or removal of the microcatheter and migration of embolic materials, can be overcome by further improvement in the endovascular procedures and devices. Complications unrelated to the endovascular technique are mainly associated with angioarchitectural characteristics of bAVMs, including eloquent cortical location or exclusive deep venous drainage. ${ }^{19}$ Baharvahdat et $\mathrm{al}^{16}$ analyzed 846 embolization procedures performed in their institution during a 10 -year period and reported that hemorrhagic complications occurred in $11 \%$ of cases, including periprocedural arterial perforation (48\%) and AVM rupture (52\%). They also identified premature venous occlusion as an independent predictor of severe hemorrhagic complication. Reportedly higher volumes of embolic agent injected in a single session and deposition on the venous outflow before complete occlusion of the bAVM could account for severe hemorrhagic complications. $^{18,28}$

In the present study, although the volume of injected liquid agent was not evaluated, the use of Onyx was not associated with higher complication rates, probably because $>60 \%$ of the 
performed endovascular procedures were planned as presurgical embolizations followed by early surgical resection of the embolized AVMs and not as a curative embolization. By contrast, preradiosurgical embolization was significantly associated with procedure-related complications in univariate statistical analysis. This finding might be because preradiosurgical embolizations are mainly performed for bAVMs in locations not suitable for surgical removal, such as AVMs in the eloquent or deepseated locations, both of which are reportedly associated with a higher risk of complications after embolization. ${ }^{19}$ The use of Onyx in such locations does not preclude complications in the preradiosurgical embolization (On-line Table 4). Considering that embolization before radiosurgery can decrease the rate of AVM obliteration, preradiosurgical AVM embolization should be decided prudently. ${ }^{29}$

Patients with infratentorial AVMs have worse outcomes than those with supratentorial lesions. ${ }^{30}$ They are more likely to present with hemorrhage, with annual rates of hemorrhage ranging from $4.4 \%$ to $11.6 \%$, compared with all AVMs (2\%-4\%), and with an annual rehemorrhage rate of $34.4 \%$ for ruptured AVMs managed conservatively. ${ }^{31}$ Infratentorial AVMs are more frequently associated with feeding artery aneurysms than supratentorial AVMs (25\% versus 5\%). ${ }^{32-34}$ Associated aneurysms are the source of bleeding in $10.5 \%$ of cases of infratentorial AVMs, but in only $1.7 \%$ of cases of supratentorial AVMs. ${ }^{34,35}$ Hemorrhages occurring from infratentorial AVMs are more likely to be symptomatic, with a mortality rate of $60 \%$ due to their presence in the narrow confines of the posterior fossa and the proximity to highly eloquent structures. ${ }^{30,31,36}$

These findings support an aggressive management for infratentorial AVMs both before and after rupture. However, infratentorial AVMs have also been reported to be difficult to treat with open surgery ${ }^{37,38}$ or stereotactic radiosurgery, ${ }^{39,40}$ and multimodal treatments including embolization have been recommended. ${ }^{41}$ The present study shows that embolization of infratentorial AVMs could also involve procedure-related complications with a significantly higher rate. Vessel tortuosity, a lower safety margin of eloquent areas, or frequent association with flow-related aneurysms might complicate embolization of infratentorial AVMs. A meticulous treatment plan is mandatory because procedure-related complications tend to be severe following the endovascular treatment of infratentorial AVMs.

The JR-NET study group previously reported the procedural complications of endovascular treatment for bAVMs (JR-NET1 and 2$)^{14}$ after analyzing the data from 987 endovascular procedures for bAVMs performed from January 2005 and December 2009. We observed some differences in the results of bAVM embolizations between the present study and JR-NET1 and JRNET2, possibly because of Onyx being approved for presurgical embolization in September 2009. As a result, Onyx was used as an embolic material in only 54 (5.5\%) procedures assessed in JRNET1 and JR-NET2, while 432 (41.5\%) procedures in the present study were performed using Onyx.

The introduction of Onyx might lead to a higher rate of AVM occlusion and procedure-related complications, changing the risk factors for endovascular treatments of bAVMs. In the present study, we did not observe any significant change in the annual rate of complete obliteration and procedure-related complications since Onyx has become widespread in the endovascular treatment of bAVMs in Japan (data not shown). Moreover, the recent advances in the field of embolization techniques such as transvenous embolization ${ }^{42}$ and the introduction of dual-lumen balloon microcatheters ${ }^{43}$ or the detachable-tip microcatheters ${ }^{44}$ for liquid embolic material are expected to improve the rate of nidus occlusion with fewer complications, though none are currently available in Japan.

This study has some limitations, including its retrospective nature and short-term follow-up period. The clinical outcomes for patients with bAVMs treated by an operation or radiosurgery after embolization were not available, so we could not determine the mRS scores 30 days after presurgical embolization to assess whether the outcomes or complications of open surgery led to any score change in these patients. Long-term outcomes, including recanalization and bleeding rates after $\mathrm{cu}-$ rative embolization, were also not available. We extracted data from JR-NET3, which includes the data from 111 major neurointerventional registered centers but may not represent the nationwide total. Future studies evaluating the long-term clinical outcomes, including recanalization and bleeding rates after embolizations, may be warranted, and further analysis could include a heterogeneous population of multiple medical centers in Japan as well as in other countries.

\section{CONCLUSIONS}

We observed that complications of endovascular treatment may result in worse outcomes in patients with bAVMs. Thus, interventionalists should be aware of potential complications, especially in the management of infratentorial AVMs.

\section{ACKNOWLEDGMENTS}

The JR-NET3 Study Group: Co-Principal Investigators: Nobuyuki Sakai, Kobe City Medical Center General Hospital, Kobe, Japan; Koji Iihara, Kyushu University, Fukuoka, Japan; and Tetsu Satow, National Cerebral and Cardiovascular Center, Suita, Japan; Investigators: Masayuki Ezura, Sendai Medical Center, Sendai, Japan; Akio Hyodo, Dokkyo Medical University Saitama Medical Center, Koshigaya, Japan; Shigeru Miyachi, Aichi Medical University, Aichi, Japan; Susumu Miyamoto, Kyoto University, Kyoto, Japan; Yoji Nagai, Kobe University, Kobe, Japan; Kunihiro Nishimura, National Cerebral and Cardiovascular Center, Suita, Japan; and Kazunori Toyoda, National Cerebral and Cardiovascular Center, Suita, Japan; Coinvestigators: Toshiyuki Fujinaka, Osaka Medical Center, Osaka, Japan; Toshio Higashi, Fukuoka University, Fukuoka, Japan; Masaru Hirohata, Kurume University, Kurume, Japan; Akira Ishii, Kyoto University, Kyoto, Japan; Hirotoshi Imamura, Kobe City Medical Center General Hospital, Kobe, Japan; Yasushi Ito, Shinrakuen Hospital, Niigata, Japan; Naoya Kuwayama, Toyama University, Toyama, Japan; Hidenori Oishi, Juntendo University, Tokyo, Japan; Yuji Matsumaru, Tsukuba University, Tsukuba, Japan; Yasushi Matsumoto, Kohnan Hospital, Sendai, Japan; Ichiro Nakahara, Fujita Medical University, Aichi, Japan; Chiaki Sakai, Hyogo College of Medicine, Nishinomiya, Japan; Kenji Sugiu, Okayama University, Okayama, Japan; Tomoaki Terada, Showa University Fujigaoka Hospital, Kanagawa, Japan; Shinichi Yoshimura, 
Hyogo College of Medicine, Nishinomiya, Japan; and Certified Specialist of Japanese Society of Neuroendovascular Therapy.

Disclosures: Yasushi Matsumoto-UNRELATED: Payment for Lectures Including Service on Speakers Bureaus: Medtronic, Stryker, Medicos Hirata, KANEKA MEDIX. Nobuyuki Sakai-RELATED: Grant: Terumo; UNRELATED: Board Membership: Terumo; Consultancy: BioMedical Solutions; Grants/Grants Pending: Daiichi-Sankyo, Terumo*; Payment for Lectures Including Service on Speakers Bureaus: Medtronic, Stryker, Terumo. Koji lihara-UNRELATED: Biomedical Solutions: practical research project for lifestyle-related diseases by the Japan Agency for Medical Research and Development, grants-in-aid from the Japanese Ministry of Health, Labor and Welfare, KAKENHI. *Money paid to the institution.

\section{REFERENCES}

1. Fleetwood IG, Steinberg GK. Arteriovenous malformations. Lancet 2002;359:863-73 CrossRef Medline

2. Arteriovenous Malformation Study Group. Arteriovenous malformations of the brain in adults. N Engl J Med 1999;340:1812-18 CrossRef Medline

3. Brown RD Jr, Wiebers DO, Forbes G, et al. The natural history of unruptured intracranial arteriovenous malformations. J Neurosurg 1988;68:352-57 CrossRef Medline

4. Mast H, Young WL, Koennecke HC, et al. Risk of spontaneous haemorrhage after diagnosis of cerebral arteriovenous malformation. Lancet 1997;350:1065-68 CrossRef Medline

5. Ondra SL, Troupp H, George ED, et al. The natural history of symptomatic arteriovenous malformations of the brain: a 24-year follow-up assessment. J Neurosurg 1990;73:387-91 CrossRef Medline

6. Gross BA, Du R. Natural history of cerebral arteriovenous malformations: a meta-analysis. J Neurosurg 2013;118:437-43 CrossRef Medline

7. Darsaut TH, Guzman R, Marcellus ML, et al. Management of pediatric intracranial arteriovenous malformations: experience with multimodality therapy. Neurosurgery 2011;69:540-56 CrossRef Medline

8. Ogilvy CS, Stieg PE, Awad I, et al; Special Writing Group of the Stroke Council, American Stroke Association. AHA Scientific Statement: recommendations for the management of intracranial arteriovenous malformations-a statement for healthcare professionals from a special writing group of the Stroke Council, American Stroke Association. Stroke 2001;32:1458-71 CrossRef Medline

9. Alexander MD, Hippe DS, Cooke DL, et al. Targeted embolization of aneurysms associated with brain arteriovenous malformations at high risk for surgical resection: a case-control study. Neurosurgery 2018;82:343-49 CrossRef Medline

10. Potts MB, Zumofen DW, Raz E, et al. Curing arteriovenous malformations using embolization. Neurosurg Focus 2014;37:E19 CrossRef Medline

11. van Rooij WJ, Jacobs S, Sluzewski M, et al. Curative embolization of brain arteriovenous malformations with Onyx: patient selection, embolization technique, and results. AJNR Am J Neuroradiol 2012;33:1299-304 CrossRef Medline

12. Valavanis A, Yaş argil MG. The endovascular treatment of brain arteriovenous malformations. Adv Tech Stand Neurosurg 1998;24:131-214 CrossRef Medline

13. Sakai N, Yoshimura S, Taki W, et al; Japanese Registry of Neuroendovascular Therapy Investigators. Recent trends in neuroendovascular therapy in Japan: analysis of a nationwide survey: Japanese Registry of Neuroendovascular Therapy (JR-NET) 1 and 2. Neurol Med Chir (Tokyo) 2014;54:1-8 CrossRef Medline

14. Kondo R, Matsumoto Y, Endo H, et al. Endovascular embolization of cerebral arteriovenous malformations: results of the Japanese Registry of Neuroendovascular Therapy (JR-NET) 1 and 2. Neurol Med Chir (Tokyo) 2014;54:54-62 CrossRef

15. Spetzler RF, Martin NA. A proposed grading system for arteriovenous malformations. J Neurosurg 1986;65:476-83 CrossRef Medline
16. Baharvahdat $H$, Blanc $R$, Termechi $R$, et al. Hemorrhagic complications after endovascular treatment of cerebral arteriovenous malformations. AJNR Am J Neuroradiol 2014;35:978-83 CrossRef Medline

17. Cronqvist M, Wirestam R, Ramgren B, et al. Endovascular treatment of intracerebral arteriovenous malformations: procedural safety, complications, and results evaluated by MR imaging, including diffusion and perfusion imaging. AJNR Am J Neuroradiol 2006;27:162-76 Medline

18. Ovalle F, Shay SD, Mericle RA. Delayed intracerebral hemorrhage after uneventful embolization of brain arteriovenous malformations is related to volume of embolic agent administered: multivariate analysis of $\mathbf{1 3}$ predictive factors. Neurosurgery 2012;70:313-20 CrossRef Medline

19. Pan J, He H, Feng L, et al. Angioarchitectural characteristics associated with complications of embolization in supratentorial brain arteriovenous malformation. AJNR Am J Neuroradiol 2014;35:35459 CrossRef Medline

20. Panagiotopoulos V, Gizewski E, Asgari S, et al. Embolization of intracranial arteriovenous malformations with ethylene-vinyl alcohol copolymer (Onyx). AJNR Am J Neuroradiol 2009;30:99-106 CrossRef Medline

21. Saatci I, Geyik S, Yavuz K, et al. Endovascular treatment of brain arteriovenous malformations with prolonged intranidal Onyx injection technique: long-term results in $\mathbf{3 5 0}$ consecutive patients with complete endovascular treatment course. J Neurosurg 2011;115:7888 CrossRef Medline

22. Starke RM, Komotar RJ, Otten ML, et al. Adjuvant embolization with N-butyl cyanoacrylate in the treatment of cerebral arteriovenous malformations: outcomes, complications, and predictors of neurologic deficits. Stroke 2009;40:2783-90 CrossRef Medline

23. Crowley RW, Ducruet AF, McDougall CG, et al. Endovascular advances for brain arteriovenous malformations. Neurosurgery 2014;74:S74-82 CrossRef Medline

24. Van Beijnum J, van der Worp HB, Buis DR, et al. Treatment of brain arteriovenous malformations: a systematic review and meta-analysis. JAMA 2011;306:2011-19 CrossRef Medline

25. Bell DL, Leslie-Mazwi TM, Yoo AJ, et al. Application of a novel brain arteriovenous malformation endovascular grading scale for transarterial embolization. AJNR Am J Neuroradiol 2015;36:130309 CrossRef Medline

26. Kim LJ, Albuquerque FC, Spetzler RF, et al. Postembolization neurological deficits in cerebral arteriovenous malformations: stratification by arteriovenous malformation grade. Neurosurgery 2006;58:53-59; discussion 53-59 CrossRef Medline

27. Hartmann A, Pile-Spellman J, Stapf C, et al. Risk of endovascular treatment of brain arteriovenous malformations. Stroke 2002;33:1816-20 CrossRef Medline

28. Heidenreich JO, Hartlieb S, Stendel R, et al. Bleeding complications after endovascular therapy of cerebral arteriovenous malformations. AJNR Am J Neuroradiol 2006;27:313-16 Medline

29. Xu F, Zhong J, Ray A, et al. Stereotactic radiosurgery with and without embolization for intracranial arteriovenous malformations: a systematic review and meta-analysis. Neurosurg Focus 2014;37:E16 CrossRef Medline

30. Abla AA, Nelson J, Rutledge WC, et al. The natural history of AVM hemorrhage in the posterior fossa: comparison of hematoma volumes and neurological outcomes in patients with ruptured infraand supratentorial AVMs. Neurosurg Focus 2014;37:E6 CrossRef Medline

31. Arnaout OM, Gross BA, Eddleman CS, et al. Posterior fossa arteriovenous malformations. Neurosurg Focus 2009;26:E12 CrossRef Medline

32. Kouznetsov E, Weill A, Ghostine JS, et al. Association between posterior fossa arteriovenous malformations and prenidal aneurysm rupture: potential impact on management. Neurosurg Focus 2014; 37:E4 CrossRef Medline 
33. Westphal M, Grzyska U. Clinical significance of pedicle aneurysms on feeding vessels, especially those located in infratentorial arteriovenous malformations. J Neurosurg 2000;92:995-1001 CrossRef Medline

34. Schmidt NO, Reitz M, Raimund F, et al. Clinical relevance of associated aneurysms with arteriovenous malformations of the posterior fossa. Acta Neurochir Suppl 2011;112:131-35 CrossRef Medline

35. da Costa L, Thines L, Dehdashti AR, et al. Management and clinical outcome of posterior fossa arteriovenous malformations: report on a single-centre 15-year experience. J Neurol Neurosurg Psychiatry 2009;80:376-79 CrossRef Medline

36. Fults D, Kelly DL Jr. Natural history of arteriovenous malformations of the brain: a clinical study. Neurosurgery 1984;15:658-62 CrossRef Medline

37. Rodríguez-Hernández A, Kim H, Pourmohamad T, et al; University of California, San Francisco Arteriovenous Malformation Study Project. Cerebellar arteriovenous malformations: anatomic subtypes, surgical results, and increased predictive accuracy of the supplementary grading system. Neurosurgery 2012;71:1111-24 CrossRef Medline

38. Han SJ, Englot DJ, Kim H, et al. Brainstem arteriovenous malformations: anatomical subtypes, assessment of "occlusion in situ" technique, and microsurgical results. J Neurosurg 2015;122:107-17 CrossRef Medline

39. Bowden G, Kano H, Tonetti D, et al. Stereotactic radiosurgery for arteriovenous malformations of the cerebellum. J Neurosurg 2014;120:583-90 CrossRef Medline

40. Koga $T$, Shin M, Terahara A, et al. Outcomes of radiosurgery for brainstem arteriovenous malformations. Neurosurgery 2011;69:4551 CrossRef Medline

41. Kelly ME, Guzman R, Sinclair J, et al. Multimodality treatment of posterior fossa arteriovenous malformations. J Neurosurg 2008;108:1152-61 CrossRef Medline

42. Mendes GA, Kalani MY, Iosif C, et al. Transvenous curative embolization of cerebral arteriovenous malformations: a prospective cohort study. Neurosurgery 2018;83:957-64 CrossRef Medline

43. Spiotta AM, James RF, Lowe SR, et al. Balloon-augmented Onyx embolization of cerebral arteriovenous malformations using a dual-lumen balloon: a multicenter experience. J Neurointerv Surg 2015;7:721-27 CrossRef Medline

44. Flores BC, See AP, Weiner GM, et al. Use of Apollo detachabletip microcatheter for endovascular embolization of arteriovenous malformations and arteriovenous fistulas. J Neurosurg 2018;130:963-71 CrossRef Medline 